\title{
Langmuir
}

\author{
pubs.acs.org/Langmuir
}

(C) 2009 American Chemical Society

\section{Polymer Multilayer Films Obtained by Electrochemically Catalyzed Click Chemistry}

\author{
Gaulthier Rydzek, ${ }^{\dagger}$ Jean-Sébastien Thomann, ${ }^{\star}$ Nejla Ben Ameur ${ }^{\star}$ Loïc Jierry, ${ }^{\dagger}$ Philippe Mésini, ${ }^{\dagger}$ \\ Arnaud Ponche,${ }^{\S}$ Christophe Contal, ${ }^{\dagger}$ Alae E. El Haitami,,${ }^{\|, \perp}$ Jean-Claude Voegel,,,$\perp$ \\ Bernard Senger, ${ }^{\|, \perp}$ Pierre Schaaf, ${ }^{* \dagger}{ }^{\dagger}$ Benoît Frisch, ${ }^{\star}$ and Fouzia Boulmedais ${ }^{\dagger}$ \\ ${ }^{\dagger}$ Centre National de la Recherche Scientifique, Unité Propre de Recherche 22, Institut Charles Sadron, \\ 23 rue du Loess, BP 84047, 67034 Strasbourg Cedex 2, France, "Laboratoire de Conception et Application de \\ Molécules Bioactives, UMR 7199, CNRS/Université de Strasbourg, Faculté de Pharmacie, 74 route du Rhin, \\ 67401 Illkirch Cedex, France, ${ }^{\S}$ Institut de Science des Matériaux de Mulhouse (IS2M), CNRS LRC7228, \\ 15 rue Jean Starcky - BP 2488, 68057 Mulhouse Cedex, France, "Institut National de la Santé et de la Recherche \\ Médicale, Unité 977, 11 rue Humann, 67085 Strasbourg Cedex, France, and ${ }^{\perp}$ Université de Strasbourg, \\ Faculté de Chirurgie Dentaire, 1 place de l'Hôpital, 67000 Strasbourg, France
}

Received August 4, 2009. Revised Manuscript Received November 16, 2009

\begin{abstract}
We report the covalent layer-by-layer construction of polyelectrolyte multilayer (PEM) films by using an efficient electrochemically triggered Sharpless click reaction. The click reaction is catalyzed by $\mathrm{Cu}(\mathrm{I})$ which is generated in situ from $\mathrm{Cu}(\mathrm{II})$ (originating from the dissolution of $\mathrm{CuSO}_{4}$ ) at the electrode constituting the substrate of the film. The film buildup can be controlled by the application of a mild potential inducing the reduction of $\mathrm{Cu}(\mathrm{II})$ to $\mathrm{Cu}(\mathrm{I})$ in the absence of any reducing agent or any ligand. The experiments were carried out in an electrochemical quartz crystal microbalance cell which allows both to apply a controlled potential on a gold electrode and to follow the mass deposited on the electrode through the quartz crystal microbalance. Poly(acrylic acid) (PAA) modified with either alkyne $\left(\mathrm{PAA}_{\mathrm{Alk}}\right)$ or azide $\left(\mathrm{PAA}_{\mathrm{Az}}\right)$ functions grafted onto the PAA backbone through ethylene glycol arms were used to build the PEM films. Construction takes place on gold electrodes whose potentials are more negative than a critical value, which lies between -70 and $-150 \mathrm{mV}$ vs $\mathrm{Ag} / \mathrm{AgCl}$ ( $\mathrm{KCl}$ sat.) reference electrode. The film thickness increment per bilayer appears independent of the applied voltage as long as it is more negative than the critical potential, but it depends upon $\mathrm{Cu}(\mathrm{II})$ and polyelectrolyte concentrations in solution and upon the reduction time of $\mathrm{Cu}(\mathrm{II})$ during each deposition step. An increase of any of these latter parameters leads to an increase of the mass deposited per layer. For given buildup conditions, the construction levels off after a given number of deposition steps which increases with the $\mathrm{Cu}(\mathrm{II})$ concentration and/or the $\mathrm{Cu}(\mathrm{II})$ reduction time. A model based on the diffusion of $\mathrm{Cu}(\mathrm{II})$ and $\mathrm{Cu}(\mathrm{I})$ ions through the film and the dynamics of the polyelectrolyte anchoring on the film, during the reduction period of $\mathrm{Cu}(\mathrm{II})$, is proposed to explain the major buildup features.
\end{abstract}

\section{Introduction}

The step-by-step deposition of interacting polymers leads to the formation of so-called polymer multilayer films. The interactions can be of electrostatic origin, ${ }^{1-6}$ due to hydrogen bonds, ${ }^{7-11}$ controlled by electrochemical deposition, ${ }^{12,13}$ or even be covalent bonds. ${ }^{10,14}$ Covalent bonds between the different multilayer

*Corresponding author: $\mathrm{Ph}+33$ (0)3 884140 12; Fax +33 (0)3 884140 99; e-mail schaaf@ics.u-strasbg.fr.

(1) Decher, G. Science 1997, 277, 1232

(2) Schlenoff, J. B.; Dubas, S. T. Macromolecules 2001, 34, 592

(3) Ladam, G.; Schaad, P.; Voegel, J.-C.; Schaaf, P.; Decher, G.; Cuisinier, F. J. G. Langmuir 2000, 16, 1249 .

(4) Kujawa, P.; Moraille, P.; Sanchez, J.; Badia, A.; Winnik, F. M. J. Am. Chem. Soc. 2005, 127, 9224

(5) Shiratori, S. S.; Rubner, M. F. Macromolecules 2000, 33, 4213.

(6) Hammond, P. T. Curr. Opin. Colloid Interface Sci. 1999, 4, 430.

(7) Stockton, W. B.; Rubner, M. F. Macromolecules 1997, 30, 2717

(8) Sukhishvili, S. A.; Granick, S. Macromolecules 2002, 35, 301.

(9) Quinn, J. F.; Caruso, F. Langmuir 2004, 20, 20.

(10) Quinn, J. F.; Johnston, A. P. R.; Such, G. K.; Zelikin, A. N.; Caruso, F. Chem. Soc. Rev. 2007, 36, 707.

(11) Kharlampieva, E.; Kozlovskaya, V.; Sukhishvili, S. A. Adv. Mater. 2009, 21,3053 .

(12) Cheng, L.; Dong, S. J. Electrochem. Commun. 1999, 1, 159.

(13) Ngankam, A. P.; Van Tassel, P. R. Langmuir 2005, 21, 5865

(14) Zhang, X.; Chen, H.; Zhang, H. Chem. Commun. 2007, 1395.

(15) Zelikin, A. N.; Li, Q.; Caruso, F. Chem. Mater. 2008, 20, 2655

(16) Zhang, Y. J.; Guan, Y.; Zhou, S. Q. Biomacromolecules 2005, 6, 2365.

(17) Tong, W. J.; Gao, C. Y.; Mohwald, H. Chem. Mater. 2005, 17, 4610. constituents, even with single component polymer, ${ }^{15-18}$ are introduced in order to increase the chemical and mechanical stability of the films. ${ }^{19,20}$ This can be done once the multilayer is built by cross-linking the electrostatically interacting polyelectrolytes, ${ }^{19-21}$ by cross-linking hydrogen-bonded multilayers, in particular poly(vinylpyrolidone) and poly(methacrylic acid) multilayers using carbodiimide chemistry, a system extensively investigated by the group of Sukhishvili, ${ }^{22-24}$ or step-by-step during the buildup process involving the formation of covalent bonds between the interacting polymers. For this latter case, various reactions were already used, ${ }^{25-28}$ and they share the

(18) Tong, W. J.; Gao, C. Y.; Möhwald, H. Macromolecules 2006, 39, 335.

(19) Richert, L.; Boulmedais, F.; Lavalle, P.; Mutterer, J.; Ferreux, E.; Decher, G.; Schaaf, P.; Voegel, J.-C.; Picart, C. Biomacromolecules 2004, 5, 284.

(20) Francius, G.; Hemmerlé, J.; Ohayon, J.; Schaaf, P.; Voegel, J.-C.; Picart, C.; Senger, B. Microsc. Res. Tech. 2006, 69, 84

(21) Yang, S. Y.; Rubner, M. F. J. Am. Chem. Soc. 2002, 124, 2100.

(22) Kozlovskaya, V.; Kharlampieva, E.; Mansfield, M. L.; Sukhishvili, S. A. Chem. Mater. 2006, 18, 328.

(23) Kharlampieva, E.; Erel-Unal, I.; Sukhishvili, S. A. Langmuir 2007, 23, 175. (24) Elsner, N.; Kozlovskaya, V.; Sukhishvili, S. A.; Fery, A. Soft Matter 2006, 2,966 .

(25) Tong, W. J.; Gao, C. Y.; Möhwald, H. Colloid Polym. Sci. 2008, 286, 1103. (26) Liu, Y. L.; Bruening, M. L.; Bergbreiter, D. E.; Crooks, R. M. Angew. Chem., Int. Ed. Engl. 1997, 36, 2114.

(27) Serizawa, T.; Nanameki, K.; Yamamoto, K.; Akashi, M. Macromol. Rapid Commun. 2002, 35, 2184-2189.

(28) Buck, M. E.; Zhang, J.; Lynn, D. M. Adv. Mater. 2007, 19, 3951. 
common property to be fast. $\mathrm{Cu}(\mathrm{I})$-catalyzed azide-alkyne $[3+$ 2] cycloaddition leading to 1,2,3-triazole bonds is one of them. This reaction, first introduced by Huisgen, also known as "click reaction", has captured over the past years a large interest from the community for functionalization purposes. ${ }^{29,30}$ It presents the advantages to be very chemoselective, to proceed with high yields in mild conditions and in highly diluted aqueous solutions. The resulting triazole functions are extremely resistant to hydrolysis, oxidation, and reduction. ${ }^{30}$ Because of the thermodynamic instability of $\mathrm{Cu}(\mathrm{I}), \mathrm{Cu}(\mathrm{II})$ is used to be reduced in situ to $\mathrm{Cu}(\mathrm{I})$, implying the addition of reducing agents (e.g., sodium ascorbate) and/or of organic ligands. ${ }^{31}$

This reaction was, in particular, used for the buildup of covalent layer-by-layer multilayers. Caruso's group was the first to introduce this buildup method to construct films entirely constituted of poly(acrylic acid) (PAA), functionalized with azide or alkyne groups, ${ }^{32}$ and to prepare antifouling microcapsules that respond to $\mathrm{pH}$ by changing their size. ${ }^{33,34}$ The swelling and shrinking of similar films was investigated by Tang et al., ${ }^{35}$ who studied the dynamic response of the multilayers to $\mathrm{pH}$ changes through a Belousov-Zhabotinsky reaction. Bergbreiter et al. ${ }^{36,37}$ fabricated temperature-responsive films made of PNIPAM chains with grafted azide or alkyne groups. Hawker's group made also use of this strategy to build layer-by-layer assemblies of azide- and alkyne-terminated dendrimers. ${ }^{38}$ Nevertheless, from a practical point of view, the step-by-step film construction using click chemistry commonly used in the literature is rather tedious. Indeed, the instability of both $\mathrm{Cu}(\mathrm{I})$ and sodium ascorbate in solution implies to prepare fresh catalytic mixtures at each step of the buildup. ${ }^{32-36,39}$ This drawback considerably reduces the interest of this methodology for the step-by-step buildup of thin films.

Electrochemically triggered Sharpless reaction was used by Collman et al. ${ }^{40}$ to attach ethynylferrocene on azide-terminated self-assembled monolayers (SAMs). SAMs were deposited on a gold-coated electrode which was held at $-300 \mathrm{mV}$ vs $\mathrm{Ag} / \mathrm{AgCl}$ reference electrode to form $\mathrm{Cu}$ (I) from $\mathrm{Cu}$ (II). The electrochemical production of $\mathrm{Cu}(\mathrm{I})$ was also used by $\mathrm{Ku}$ et al. ${ }^{41}$ to pattern azidofunctionalized glass substrates by scanning electrochemical microscopy using a gold ultramicroelectrode. In both studies, the authors used $\mathrm{Cu}$ (II) in the presence of a ligand in an aqueous solution or in DMF solvent. In another study, Finn's group showed that the electrochemical monitoring of the $\mathrm{Cu}(\mathrm{I})$-catalyzed alkyne-azide cycloaddition is also possible between two functionalized molecules in the bulk containing $\mathrm{CuSO}_{4}$ with or without ligand. ${ }^{42}$ 2004

(30) Kolb, H. C.; Sharpless, K. B. Drug Discovery Today 2003, 8, 1128

(31) Diez-Gonzalez, S.; Correa, A.; Cavallo, L.; Nolan, S. P. Chem.-Eur. J. 2006, 12,7558

(32) Such, G. K.; Quinn, J. F.; Quinn, A.; Tjipto, E.; Caruso, F. J. Am. Chem. Soc. 2006, 128,9318

(33) Such, G. K.; Tjipto, E.; Postma, A.; Johnston, A. P. R.; Caruso, F. Nano Lett. 2007, 7, 1706.

(34) Ochs, C. J.; Such, G. K.; Stadler, B.; Caruso, F. Biomacromolecules 2008, 9, 3389.

(35) Tang, Y. C.; Liu, G. M.; Yu, C. Q.; Wei, X. L.; Zhang, G. Z. Langmuir 2008, 24,8929

(36) Bergbreiter, D. E.; Chance, B. S. Macromolecules 2007, 40, 5337

(37) Bergbreiter, D. E.; Liao, K. S. Soft Matter 2009, 5, 23.

(38) Vestberg, R.; Malkoch, M.; Kade, M.; Wu, P.; Fokin, V. V.; Sharpless, K. B.; Drockenmuller, E.; Hawker, C. J. J. Polym. Sci., Part A: Polym. Chem. 2007, 45,2835 .

(39) Kinnane, C. R.; Wark, K.; Such, G. K.; Johnston, A. P. R.; Caruso, F. Small 2009, 5, 444

(40) Devaraj, N. K.; Dinolfo, P. H.; Chidsey, C. E. D.; Collman, J. P. J. Am. Chem. Soc. 2006, 128, 1794.

(41) Ku, S. Y.; Wong, K. T.; Bard, A. J. J. Am. Chem. Soc. 2008, 130, 2392.

(42) Hong, V.; Udit, A. K.; Evans, R. A.; Finn, M. G. ChemBioChem 2008, 9 , 1481.
Here, we report the covalent layer-by-layer construction of a polyelectrolyte multilayer (PEM) film by using the click reaction triggered by electrochemistry in the sole presence of $\mathrm{CuSO}_{4}$ $(\mathrm{Cu}$ (II) ions). By using an electric potential applied on the substrate (gold electrode), we induce and control the formation of $\mathrm{Cu}(\mathrm{I})$ ions from $\mathrm{Cu}(\mathrm{II})$ ions. The $\mathrm{Cu}(\mathrm{I})$-catalyzed click reaction is thus performed without any reducing agent and ligand by applying a mild electric potential (Scheme 1). The deposition and dissolution of $\mathrm{Cu}(0)$ on and from an electrode are complex processes whose details are still under debate. ${ }^{43-46}$ However, what seems to be firmly established is that the reduction reaction of $\mathrm{Cu}(\mathrm{II})$ into $\mathrm{Cu}(0)$ is a multistep process that involves $\mathrm{Cu}(\mathrm{I})$ which diffuses in the solution near the electrode. This $\mathrm{Cu}(\mathrm{I})$ diffusion could induce a fast and localized click reaction and thus a fast and localized film buildup. Moreover, this could allow selectively and independently functionalizing microelectrodes from an array with different polymer multilayer films by simply applying a reduction potential on the desired microelectrodes. Electrically induced "conventional" noncovalent polyelectrolyte multilayer films were reported where the electric field was used to obtain selective deposition. ${ }^{12,13,47-53}$ Our approach constitutes an alternative to these methods with the advantage to create a "covalent" multilayer film.

\section{Materials and Methods}

Polyelectrolyte Solutions. We used PAA modified with either alkyne (PAA Alk: $_{\text {PAA-(EG) }}$-Alk) or azide $\left(\mathrm{PAA}_{\mathrm{Az}}\right.$ : PAA-(EG) $12-\mathrm{Az})$ functions grafted onto the PAA backbone through ethylene glycol EG arms and PEI modified by azide functions $\left(\mathrm{PEI}_{\mathrm{Az}}\right)$ at a grafting ratio of $6 \%$ (Scheme 2). The details of their synthesis can be found in the Supporting Information.

The $\mathrm{PEI}_{\mathrm{Az}}-\left(\mathrm{PAA}_{\mathrm{Alk}} / \mathrm{PAA}_{\mathrm{Az}}\right)_{n}$ polyelectrolyte architectures, where $n$ is the number of deposition cycles corresponding to the deposition of $n \mathrm{PAA}_{\mathrm{Alk}} / \mathrm{PAA}_{\mathrm{Az}}$ pairs of layers, were built as follows. Polyelectrolyte solutions at $0.5 \mathrm{mg} / \mathrm{mL}$ were prepared by dissolution of the adequate masses of polyelectrolytes in filtered (Millex GV membranes, pore diameter of $0.22 \mu \mathrm{m}$ ) solutions of $\mathrm{CuSO}_{4}(0.3 \mathrm{mM})$ adjusted to $\mathrm{pH} 3.5 \pm 0.05$ using diluted $\mathrm{HNO}_{3}$ solution. In the case of lower $\mathrm{CuSO}_{4}$ concentrations, $\mathrm{NaNO}_{3}$ salt was added in aqueous solution to maintain the ionic strength constant (the ionic strength of $0.3 \mathrm{mM}$ of $\mathrm{CuSO}_{4}$, i.e., $1.2 \mathrm{mM}$ ). The layer-by-layer (LbL) assembly was started onto a bare gold substrate by adsorbing positively charged poly(ethylenimine)-Az $\left(\mathrm{PEI}_{\mathrm{Az}}\right)$ to obtain a first electrostatic layer in order to promote further film buildup. The $\mathrm{pH}$ of the $\mathrm{PEI}_{\mathrm{Az}}$ solution was 7.0.

Electrochemical Quartz Crystal Microbalance (EC-QCM) with Dissipation Monitoring. The electrochemical quartz crystal microbalance (EC-QCM) experiments were performed on a Q-Sense E1 apparatus from Q-Sense AB (Gothenburg, Sweden)

(43) Kologo, S.; Eyraud, M.; Bonou, L.; Vacandio, F.; Massiani, Y. Electrochim. Acta 2007, 52, 3105 .

(44) Lang, G. G.; Ujvari, M.; Horanyi, G. J. Electroanal. Chem. 2002, 522, 179. (45) Soares, D. M.; Wasle, S.; Weil, K. G.; Doblhofer, K. J. Electroanal. Chem. 2002, 532,353 .

(46) Gimenez-Romero, D.; Gabrielli, C.; Garcia-Jareno, J. J.; Perrot, H.; Vicente, F. J. Electrochem. Soc. 2006, 153, J32.

(47) Sun, J. Q.; Gao, M. Y.; Feldmann, J. J. Nanosci. Nanotechnol. 2001, 1, 133 (48) Gao, M. Y.; Sun, J. Q.; Dulkeith, E.; Gaponik, N.; Lemmer, U.; Feldmann, J. Langmuir 2002, 18, 4098 .

(49) Sun, J. Q.; Gao, M. Y.; Zhu, M.; Feldmann, J.; Möhwald, H. J. Mater. Chem. 2002, 12, 1775 .

(50) Shi, L. X.; Lu, Y. X.; Sun, J.; Zhang, J.; Sun, C. Q.; Liu, J. Q.; Shen, J. C. Biomacromolecules 2003, 4, 1161.

(51) Wu, F.; Hu, Z.; Wang, L.; Xu, J.; Xian, Y.; Tian, Y.; Jin, L. Electrochem. Commun. 2008, 10, 630.

(52) Zamarreño, C. R.; Goicoechea, J.; Matías, I. R.; Arregui, F. J. Thin Solid Films 2009, 517, 3776.

(53) Ngankam, A. P.; Van Tassel, P. R. Proc. Natl. Acad. Sci. U.S.A. 2007, 104 1140. 
Scheme 1. Schematic Representation of the Polymer Multilayer Buildup Using Electrochemically Controlled Click Chemistry

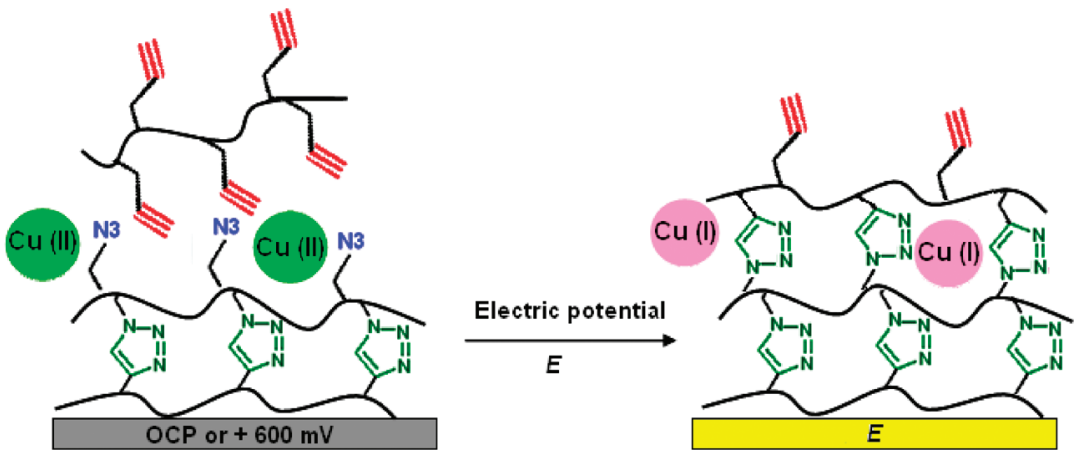

Scheme 2. Structure of $\mathbf{P A A}_{\mathrm{Alk}}, \mathbf{P A A}_{\mathrm{Az}}$, and $\mathrm{PEI}_{\mathrm{Az}}$, Used in This Study, Synthesized at a Grafting Ratio of $6 \%$

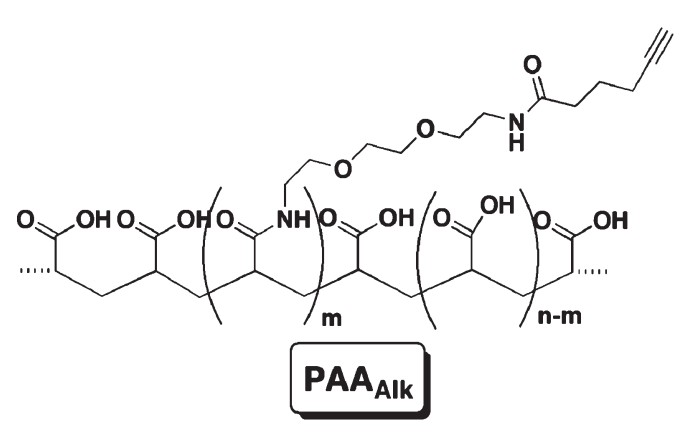<smiles>CCNCCN(CCN(C)CCN)CCN(C)CCNCCN(CCNCCNCCNC(=O)CCC(N)=O)CCNCCN(CCNCCNC)CCN(C)CCN(CCNCCN)CCNCCN(CCNCCN)CCN(C)CCNCCNCCNCCNCCN</smiles>

by monitoring the changes in the resonance frequency $f$ and the dissipation factor $D$ of an oscillating quartz crystal upon adsorption of a viscoelastic layer. ${ }^{54,55}$ The quartz crystal is excited at its fundamental frequency $(5 \mathrm{MHz})$, and the measurements are performed at the first, third, fifth, and seventh overtones, corresponding to $5,15,25$, and $35 \mathrm{MHz}$. The QCM measurement is sensitive to the amount of water associated with the adsorbed molecules and senses the viscoelastic changes in the interfacial material. ${ }^{54}$ In the Results section, only the normalized frequency shifts of the third overtone $\left(\Delta f_{3} / 3\right)$ are presented. The thickness of the adsorbed layers can be estimated using the viscoelastic Voigt model. ${ }^{56}$ For the evaluation, the fluid density $\left(1009 \mathrm{~kg} / \mathrm{m}^{3}\right)$, fluid viscosity $(0.91 \mathrm{mPa} \cdot \mathrm{s})$, and layer density $\left(1000 \mathrm{~kg} / \mathrm{m}^{3}\right)$ are kept constant. The thickness is estimated using the third, fifth, and seventh overtones. The Q-Sense Electrochemistry Module, QEM 401, allows simultaneous QCM and electrochemistry measurements. The gold-coated QCM sensor acted as working electrode. A platinum counter electrode on the top wall of the chamber and a no-leak $\mathrm{Ag} / \mathrm{AgCl}$ reference electrode fixed in the outlet flow

(54) Marx, K. A. Biomacromolecules 2003, 4, 1099.

(55) Höök, F.; Vörös, J.; Rodahl, M.; Kurrat, R.; Boni, P.; Ramsden, J. J.; Textor, M.; Spencer, N. D.; Tengvall, P.; Gold, J.; Kasemo, B. Colloids Surf., B 2002, 24, 155 .

(56) Voinova, M. V.; Rodahl, M.; Jonson, M.; Kasemo, B. Phys. Scr. 1999, 59, 391. channel were used respectively as counter and reference electrodes. Before the buildup of the polymer film, in order to test the quality of the EC-QCM cell, a capacitive current and a faradic current of $1 \mathrm{mM}$ of potassium hexacyanoferrate(II), $\mathrm{K}_{4}\left[\mathrm{Fe}(\mathrm{CN})_{6}\right]$ (Sigma, CAS 14459-95-1), aqueous solution were recorded. A Tris- $\mathrm{NaNO}_{3}$ buffer solution of tris(hydroxymethylaminomethane) (Tris, $5 \mathrm{mM}$, Gibco BRL, catalog no. 15504-020) and sodium nitrate $\left(\mathrm{NaNO}_{3}, 0.15 \mathrm{M}\right)$ adjusted at $\mathrm{pH} 7.4$ was prepared to measure the capacitive current of the EC-QCM cell. $1 \mathrm{mM}$ of potassium hexacyanoferrate(II) was prepared in Tris $-\mathrm{NaNO}_{3}$ buffer solution and put into contact with the crystal to monitor its cyclic voltammogram. The buildup was operated as described in the text. The change in $\mathrm{pH}$ of the solution in contact with the film was obtained by injecting under flow rate of $1 \mathrm{~mL} / \mathrm{min} 10 \mathrm{mM}$ $\mathrm{NaNO}_{3}$ solution at the desired $\mathrm{pH}$.

Atomic Force Microscopy. Multilayer samples, to be studied by atomic force microscopy (AFM) in a liquid cell, were built on the QCM quartz crystal inside the EC-QCM apparatus. AFM images were obtained in contact mode in liquid conditions in the presence of $10 \mathrm{mM} \mathrm{NaNO}_{3}$ at $\mathrm{pH} 3.5$ or $\mathrm{pH} 9$ with the Nanoscope IV from Veeco (Santa Barbara, CA). No Cu(II) was present in the solution while performing the AFM measurements. Cantilevers with a spring constant of $0.03 \mathrm{~N} / \mathrm{m}$ and silicon nitride tip (model MSCTAUHW, Veeco) were used. We always performed several scans over a given surface area. These scans had to 

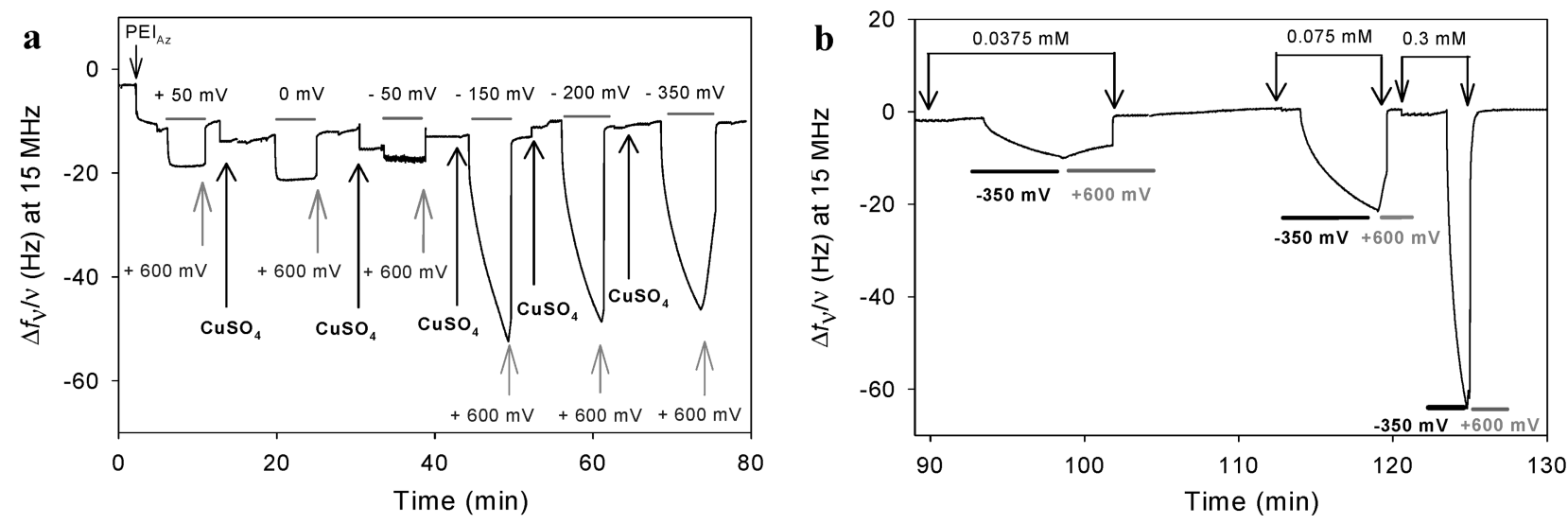

Figure 1. (a) Evolution of the normalized frequency shift in the presence of $0.3 \mathrm{mM} \mathrm{CuSO}_{4}$ solution, measured at $15 \mathrm{MHz}(v=3)$ by EC$\mathrm{QCM}$, as a function of time. After the adsorption of a monolayer of $\mathrm{PEI}_{\mathrm{Az}}$, we applied electrical potentials, step by step, from +50 to $-350 \mathrm{mV}$ alternated with the application of $+600 \mathrm{mV}$. (b) Evolution of the normalized frequency shift, measured at $15 \mathrm{MHz}$ by EC-QCM, as a function of time where $\mathrm{CuSO}_{4}$ solutions of different concentrations were injected one after the other on a PEI $\mathrm{Az}_{\mathrm{z}}$ monolayer. For each solution, we applied consecutively -350 and $+600 \mathrm{mV}$ versus $\mathrm{Ag} / \mathrm{AgCl}$. For the sake of clarity, the mechanical perturbations of the signal due to rinsing steps, i.e., injection of $2 \mathrm{~mL}$ of a $\mathrm{CuSO}_{4}$ solution, were removed from the curve.

produce comparable images to ascertain that there is no sample damage induced by the tip. Deflection and height images $(10 \mu \mathrm{m} \times$ $10 \mu \mathrm{m})$ were scanned at a fixed scan rate $(2 \mathrm{~Hz})$ with a resolution of $512 \times 512$ pixels.

XPS Spectroscopy. XPS analysis was performed on a Gammadata Scienta (Uppsala, Sweden) SES 200-2 X-ray photoelectron spectrometer under ultrahigh vacuum $\left(P<10^{-9}\right.$ mbar $)$. The monochromatized Al $\mathrm{K} \alpha$ source $(1486.6 \mathrm{eV})$ was operated at a power of $420 \mathrm{~W}(30 \mathrm{~mA}$ and $14 \mathrm{kV})$, and the spectra were acquired at a takeoff angle (TOA) of $90^{\circ}$ (angle between the sample surface and photoemission direction). The samples were outgassed in several ultrahigh-vacuum chambers with isolated pumping systems and pressure control until transfer to the analysis chamber. During acquisition, the pass energy was set to $500 \mathrm{eV}$ for wide scans and to $100 \mathrm{eV}$ for high-resolution spectra. The $100 \mathrm{eV}$ pass energy gives an overall resolution of $0.48 \mathrm{eV}$ determined on the Fermi edge of silver sample. With the help of CASAXPS software (Casa Software Ltd., Teignmouth, UK, www.casaxps.com), atomic composition (in \%) of the sample surface is calculated using raw area corrected with classical Scofield sensitivity factors and transmission function of the spectrometer. All components on high-resolution spectra were referenced according to the $\mathrm{CH}_{x}$ component at $285.0 \mathrm{eV}$.

\section{Results}

Electrochemical Reduction of $\mathbf{C u}(\mathbf{I I})$ to $\mathbf{C u}(\mathbf{0})$. We first investigated what happens on the surface of the working electrode in contact with a $\mathrm{Cu}$ (II) solution when an electric potential is applied. After the adsorption of a $\mathrm{PEI}_{\mathrm{Az}}$ precursor layer on the gold-coated QCM crystal, the evolution of the frequency shift in contact with $0.3 \mathrm{mM} \mathrm{Cu}$ (II) solution was monitored during the step-by-step application of electric potentials ranging from +50 to $-350 \mathrm{mV}$ (all the potentials are given versus $\mathrm{Ag} / \mathrm{AgCl}(\mathrm{KCl}$ sat.)) reference electrode, as shown in Figure 1a.

Between each investigated electric potential, a potential of $+600 \mathrm{mV}$ was applied to dissolve the formed $\mathrm{Cu}(0)$ deposit. At an applied reduction potential $E$ more negative than a critical potential $\left(E_{\text {crit }}\right)$, which lies between -50 and $-150 \mathrm{mV}$, the frequency shift decreases rapidly over the whole time during which the reduction potential is applied, indicating the deposition of $\mathrm{Cu}(0)$ on the working electrode through the reduction of $\mathrm{Cu}(\mathrm{II})$. When the electric potential is raised to $+600 \mathrm{mV}$, the frequency shift increases and returns to its initial value corresponding to the bare electrode. This takes place in less than $300 \mathrm{~s}$. The whole $\mathrm{Cu}(0)$ is removed from the substrate. The oxidation and reduction cycle of the catalyst is thus completely reversible. When the applied potential $E$ is more positive than $E_{\text {crit }}$, only a small frequency shift decrease is observed initially corresponding to a small mass increase, and the signal no longer evolves with time. This small mass increase could be due to a small ion adsorption as the reduction potential is imposed, but it does not correspond to a $\mathrm{Cu}(0)$ deposition. This indicates that no reduction of $\mathrm{Cu}(\mathrm{II})$ to $\mathrm{Cu}(0)$ takes place at these potentials. The value of $E_{\text {crit }}$ for which the reduction of $\mathrm{Cu}$ (II) starts is in agreement with reported values obtained from cyclic voltammetry experiments. ${ }^{44}$ In addition, we found that for reduction potentials more negative than $E_{\text {crit }}$, the decrease of the frequency shift and thus the deposition rate of $\mathrm{Cu}(0)$ on the electrode are fairly independent of the applied potential. We also monitored the evolution of the frequency shift during the consecutive applications of $-350 \mathrm{mV}$ ( $5 \mathrm{~min})$ and $+600 \mathrm{mV}(5 \mathrm{~min})$ at different concentrations of $\mathrm{Cu}(\mathrm{II})$ in the solution. As expected, the $\mathrm{Cu}(0)$ deposition rate increases with the $\mathrm{Cu}(\mathrm{II})$ concentration in solution (Figure $1 \mathrm{~b}$ ).

Electrochemically Triggered Click Chemistry Buildup of Polymer Multilayer Films: Proof of the Concept. To build the film by electrochemically catalyzed click chemistry, we used PAA modified with either alkyne $\left(\mathrm{PAA}_{\mathrm{Alk}}\right)$ or azide $\left(\mathrm{PAA}_{\mathrm{Az}}\right)$ functions with a grafting ratio close to $6 \%$, a system close to that investigated by the group of Caruso. ${ }^{32}$ The multilayer was constructed on a $\mathrm{PEI}_{\mathrm{Az}}$ precursor layer used to anchor strongly the film on the gold electrode. Then, the substrate was alternately brought into contact with the $\mathrm{PAA}_{\mathrm{Alk}}$ and $\mathrm{PAA}_{\mathrm{Az}}$ solutions, both containing $\mathrm{CuSO}_{4}(\mathrm{Cu}(\mathrm{II}), 0.3 \mathrm{mM})$. The film buildup procedure is displayed in Scheme 3 .

When the polyelectrolyte solutions were brought into contact with the film, the electrical circuit was first kept open for $60 \mathrm{~s}$. After this time interval, the potential of the gold electrode was fixed to a given value $E$ for 300 s, during which reduction of $\mathrm{Cu}$ (II) resulting in the deposition of $\mathrm{Cu}(0)$ on the surface took place. The potential was then raised to $600 \mathrm{mV}$ for $150 \mathrm{~s}$, and the polyelectrolyte solution was replaced by a $\mathrm{CuSO}_{4}$ solution for an additional $150 \mathrm{~s}$ still at $600 \mathrm{mV}$. Finally, the electrical circuit was opened again, the $\mathrm{CuSO}_{4}$ solution was replaced by the next polyelectrolyte solution, and a new deposition step is started.

Figure 2 represents the typical evolution of the normalized frequency shift monitored by EC-QCM during the film buildup of a $\mathrm{PEI}_{\mathrm{Az}}-\left(\mathrm{PAA}_{\mathrm{Alk}} / \mathrm{PAA}_{\mathrm{Az}}\right)_{2}$ multilayer as a function of time with $E=-350 \mathrm{mV}$. After the adsorption of a $\mathrm{PEI}_{\mathrm{Az}}$ precursor 


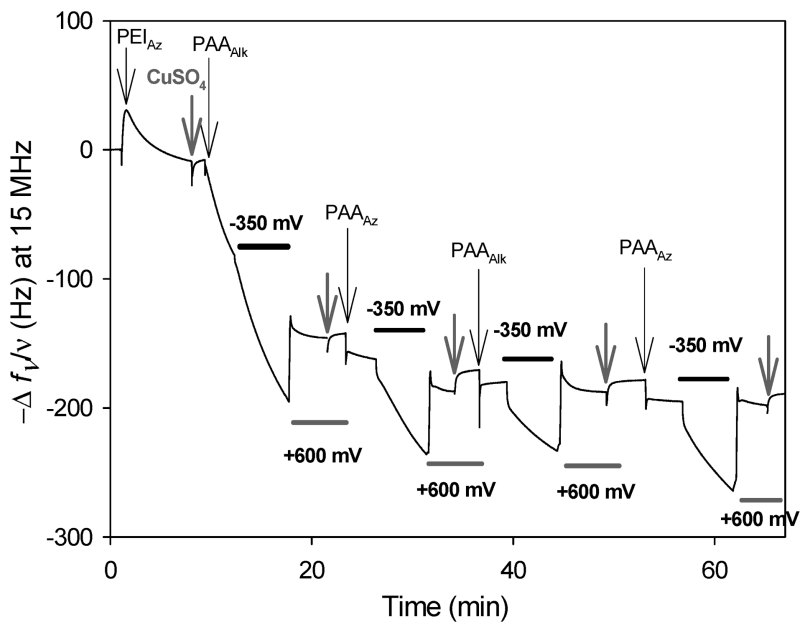

Figure 2. Evolution of the normalized frequency shift, measured at $15 \mathrm{MHz}(v=3)$ by EC-QCM, as a function of time during the buildup of a $\mathrm{PEI}_{\mathrm{Az}}-\left(\mathrm{PAA}_{\mathrm{Alk}} / \mathrm{PAA}_{\mathrm{Az}}\right)_{2}$ film. The film was built in the presence of $0.3 \mathrm{mM} \mathrm{CuSO}_{4}$ solution with the application of an electric potential of $-350 \mathrm{mV}$ during the adsorption of PAA $\mathrm{Alk}_{\mathrm{k}}$ and $\mathrm{PAA}_{\mathrm{Az}}$, followed by the application of an electric potential of $+600 \mathrm{mV}$. Each electric potential was applied for $5 \mathrm{~min}$.

Scheme 3. Standard Procedure Used for the Buildup of Films Composed of Poly(acrylic acid) Functionalized by Alkyne or Azide Functions, Using Electrochemically Catalyzed Click Chemistry ${ }^{a}$

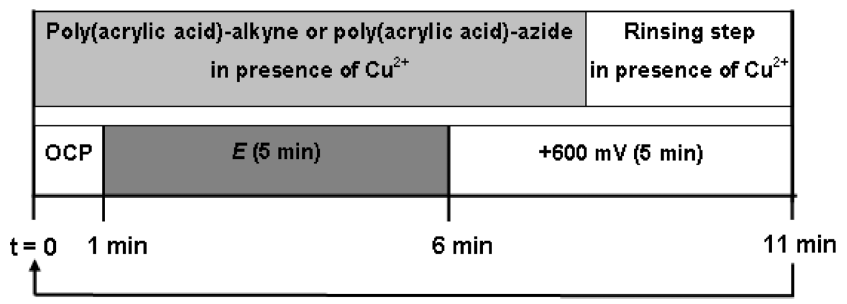

${ }^{a}$ This procedure is applied after the adsorption of a precursor layer of PEI functionalized by azide functions. OCP means open-circuit potential.

layer under "open circuit potential" (OCP) conditions, the first adsorption of $\mathrm{PAA}_{\mathrm{Alk}}$ is mainly controlled by electrostatic interactions of PAA with the precursor PEI layer leading to a high decrease of the frequency shift even before the application of $E$. A smaller decrease in frequency shifts is obtained during the following $\mathrm{PAA}_{\mathrm{Az}}$ and $\mathrm{PAA}_{\mathrm{Alk}}$ deposition steps. One can notice that the formation of $\mathrm{Cu}(0)$ during the application of the reducing potential $E$, corresponding to a rapid decrease in the frequency shift, and its subsequent removal from the surface at $+600 \mathrm{mV}$.

The evolutions of the normalized frequency shift and of the energy dissipation during the step by step construction of the $\mathrm{PEI}_{\mathrm{Az}}-\left(\mathrm{PAA}_{\mathrm{Alk}} / \mathrm{PAA}_{\mathrm{Az}}\right)_{7}$ film as a function of deposited layer are shown in Figure 3. A regular decrease of the normalized frequency shift is observed as a function of the number of deposition steps. We already proved previously that during the application of $+600 \mathrm{mV}, \mathrm{Cu}(0)$ is totally removed from a $\mathrm{PEI}_{\mathrm{Az}}$-coated substrate (Figure 1). We checked that this remains valid in the presence of a $\mathrm{PEI}_{\mathrm{Az}}-\left(\mathrm{PAA}_{\mathrm{Alk}} / \mathrm{PAA}_{\mathrm{Az}}\right)_{7}$ film by imposing successive cycles of $\mathrm{Cu}(0)$ deposition at $-350 \mathrm{mV}$ followed by $\mathrm{Cu}(0)$ removal at $+600 \mathrm{mV}$. No evolution of the frequency shift was observed between two consecutive cycles (see Figure S-1 in Supporting Information). We also performed XPS experiments on films constituted of 14 and $17 \mathrm{PAA}_{\mathrm{Alk}} / \mathrm{PAA}_{\mathrm{Az}}$ bilayers to determine the amount of copper remaining in the film. The film exhibits an atomic composition of $0.2 \%$ in $\mathrm{Cu}(\mathrm{I})$ and no trace of $\mathrm{Cu}(0)$. More details about the XPS experiments are given in

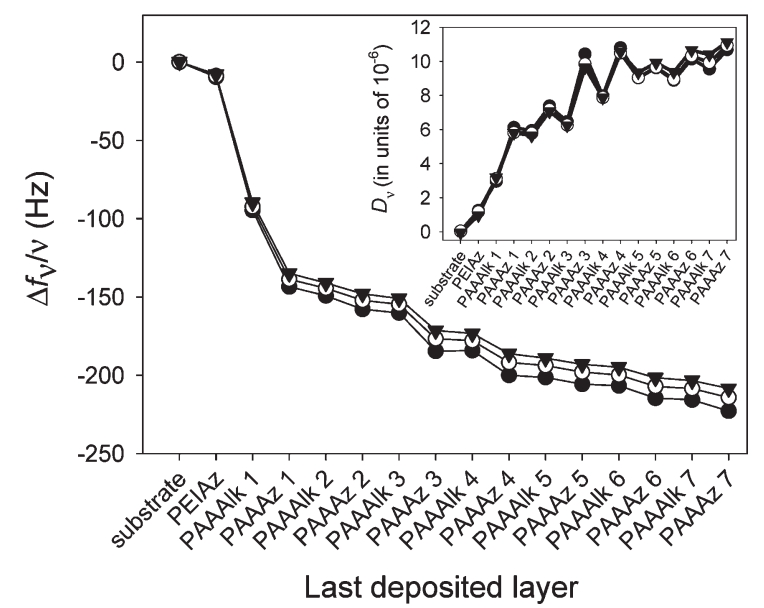

Figure 3. Typical evolution of the normalized frequency shift $\Delta f_{v} / v$ and the energy dissipation $D_{v}$ (in inset), measured by EC-QCM, as a function of the sequence of adsorbed polyelectrolyte layers $\left(\mathrm{PAA}_{\mathrm{Alk}}\right.$ or $\left.\mathrm{PAA}_{\mathrm{Az}}\right)$ at the different overtones $(v)$ of the fundamental frequency, $v=3$ at $15 \mathrm{MHz}(\bullet), v=5$ at $25 \mathrm{MHz}(\bigcirc)$, and $v=7$ at $35 \mathrm{MHz}(\boldsymbol{\nabla})$. Measurements at the fundamental frequency (5 MHz) were not considered due its sensitivity to bulk solution changes. The functionalized polyelectrolytes $\left(\mathrm{PAA}_{\mathrm{Alk}}\right.$ or $\left.\mathrm{PAA}_{\mathrm{Az}}\right)$ were adsorbed at a reduction potential of $-350 \mathrm{mV}$ in the presence of $0.3 \mathrm{mM} \mathrm{CuSO}_{4}$ solution. A $\mathrm{PEI}_{\mathrm{Az}}$ precursor layer is used to anchor the film onto the substrate.

Figure S-2 in the Supporting Information. The regular decrease of the frequency shift with the deposited layer can thus entirely be attributed to the $\mathrm{PAA}_{\mathrm{Alk}} / \mathrm{PAA}_{\mathrm{Az}}$ film buildup and not to a contribution of a small and regular $\mathrm{Cu}(0)$ deposition. This proves the buildup of multilayers by electrochemically triggered click-reaction.

Influence of the Applied Reduction Potential on the Buildup of PAA $\mathbf{A}_{\mathrm{Alk}} / \mathbf{P A A}_{\mathbf{A z}}$ Film. We investigated the film buildup as a function of the applied reduction potential $E$ (Figure 4). The $\mathrm{PAA}_{\mathrm{Alk}} / \mathrm{PAA}_{\mathrm{Az}}$ film buildup by click chemistry is electrochemically triggered as long as the voltage conditions are favorable for the reduction of $\mathrm{Cu}(\mathrm{II})$, the critical potential lying between -70 and $-150 \mathrm{mV}$. For applied potentials lower than the critical value, the film buildup appears nearly independent of the applied voltage in accordance with the same independence of the $\mathrm{Cu}(0)$ deposition rate on a bare electrode (Figure 1). As a further control of the electrochemically triggered nature of the buildup mechanism, we also performed experiments at $-350 \mathrm{mV}$ where only $\mathrm{PAA}_{\mathrm{Alk}}$ or nonfunctionalized PAA was deposited on a $\mathrm{PEI}_{\mathrm{Az}}$ precursor layer. As anticipated, in both cases the films did not buildup (see Figure S-3 in Supporting Information).

In the literature, it is not clear whether $\mathrm{Cu}(\mathrm{I})$ is formed during the reduction of $\mathrm{Cu}$ (II) to $\mathrm{Cu}(0)$ or during the oxidation of $\mathrm{Cu}(0)$ to $\mathrm{Cu}(\mathrm{II}){ }^{43,44}$ In our standard procedure, the polyelectrolyte solutions are in contact with the film during a defined time at a reduction potential followed by $150 \mathrm{~s}$ at an oxidation potential of $+600 \mathrm{mV}$; the click reaction could take place under reductive and/ or oxidative conditions. To verify this point, we performed experiments where the polyelectrolyte solution was brought in contact with the film only once the electrode potential was set to $+600 \mathrm{mV}$ (see Figure S-3 in Supporting Information). Besides the initial buildup due to electrostatic interactions between $\mathrm{PEI}_{\mathrm{Az}}$ and $\mathrm{PAA}_{\mathrm{Alk}}$, no evolution of the frequency shift was observed, indicating that the film construction does not take place. This proves that the $\mathrm{Cu}(\mathrm{I})$ production takes place only under reductive conditions of $\mathrm{Cu}(\mathrm{II})$.

Effect of the $\mathrm{CuSO}_{4}$ Concentration on the Film Buildup. We varied the $\mathrm{Cu}$ (II) concentration of the buildup solutions by 


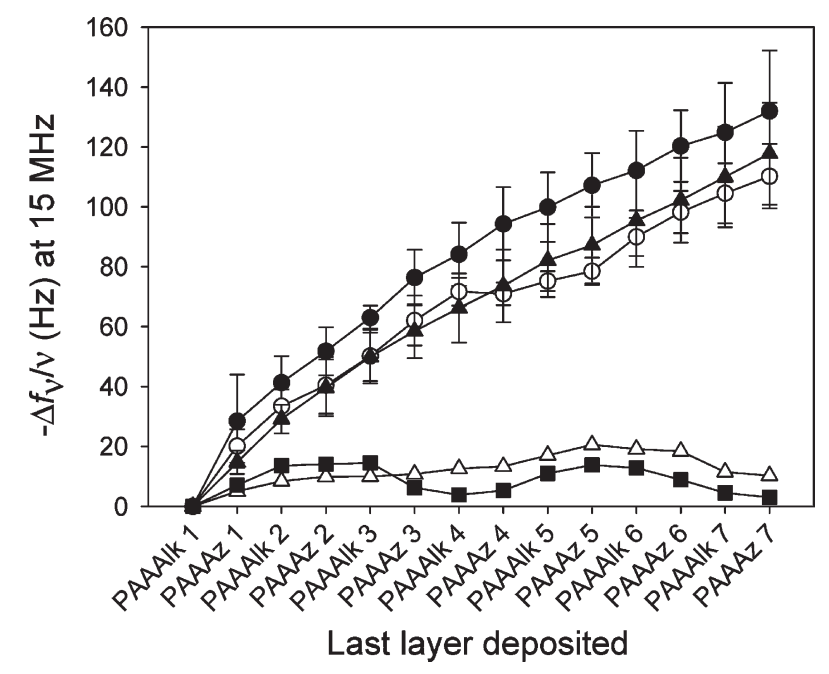

Figure 4. Evolution of the normalized frequency shift, measured at $15 \mathrm{MHz}(v=3)$ by EC-QCM, as a function of the sequence of adsorbed polyelectrolyte layers $\left(\mathrm{PAA}_{\mathrm{Alk}}\right.$ or $\left.\mathrm{PAA}_{\mathrm{Az}}\right)$ for electric potentials $E$ equal to $-350(\bullet),-200(\bigcirc),-150(\Delta),-70(\triangle)$, and $0 \mathrm{mV}(\boldsymbol{\square})$ in the presence of $0.3 \mathrm{mM} \mathrm{CuSO}_{4}$ solution. A $\mathrm{PEI}_{\mathrm{Az}}$ precursor layer is used to anchor strongly the films onto the substrate. The crystal resonance frequency corresponding to the

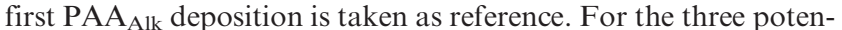
tial values where the films build up, the average and the standard deviation from at least three experiments are represented.

keeping the applied reduction potential $E$ fixed at $-350 \mathrm{mV}$ during the adsorption of $\mathrm{PAA}_{\mathrm{Alk}}$ and $\mathrm{PAA}_{\mathrm{Az}}$ (see Figure 5). The absolute value of the normalized frequency shift of $\mathrm{PAA}_{\mathrm{Alk}} /$ PAA $_{\mathrm{Az}}$ film increases upon increasing $\mathrm{Cu}$ (II) concentration in solution, indicating that the deposited mass, for a given number of deposition steps, increases when the $\mathrm{Cu}(\mathrm{II})$ concentration is increased. This result correlates well with the evolution of the $\mathrm{Cu}(0)$ deposition rate with respect to the $\mathrm{Cu}(\mathrm{II})$ concentration in solution (Figure 1b) and thus with the production of $\mathrm{Cu}(\mathrm{I})$ as a function of the $\mathrm{Cu}(\mathrm{II})$ concentration in solution during the reduction step.

The film buildup seems to level off at large numbers of deposition steps. This is particularly striking at low $\mathrm{Cu}$ (II) concentrations. To check further this point, we performed two experiments: one at $0.075 \mathrm{mM}$ and one at $0.3 \mathrm{mM}$ of $\mathrm{Cu}$ (II) over up to $14 \mathrm{PAA}_{\mathrm{Alk}} / \mathrm{PAA}_{\mathrm{Az}}$ pairs of layers. When the film was constructed with solutions of $0.075 \mathrm{mM} \mathrm{Cu}(\mathrm{II})$, the buildup leveled off after $n=10$ pairs of layers. With a concentration of $0.3 \mathrm{mM}$, we did not yet reach the leveling off up to $n=14$, but the deposition rate clearly slowed down while $n$ increased (see Figure S-4a in Supporting Information).

Effect of the Reduction Time. We investigated the effect of the reduction time $\Delta t_{E}$ over which the reduction potential $E$ is applied. This potential was kept equal to $-350 \mathrm{mV}$ and we used a $\mathrm{Cu}$ (II) concentration of $0.15 \mathrm{mM}$ for this purpose. The evolution of the frequency shift relative to the film buildup for different times are given in Figure 6.

While the film buildups are similar for 2 and $5 \mathrm{~min}$, the film thickness increases with $\Delta t_{E}$ at a given value of the number $n \mathrm{PAA}_{\mathrm{Alk}} / \mathrm{PAA}_{\mathrm{Az}}$ pairs of layers. Whereas for 2 and $5 \mathrm{~min}$ the buildup starts to level off after seven deposition steps, no tendency of leveling off is observed for longer application times up to $n=$ 7. For $\Delta t_{E}=7 \mathrm{~min}$, the leveling off took place for $n=12$ (Figure $\mathrm{S}-4 \mathrm{~b}$ in Supporting Information). One can thus assume that the value of the number of deposition steps at which the leveling off sets in increases with the reduction time $\Delta t_{E}$. A study of a precise

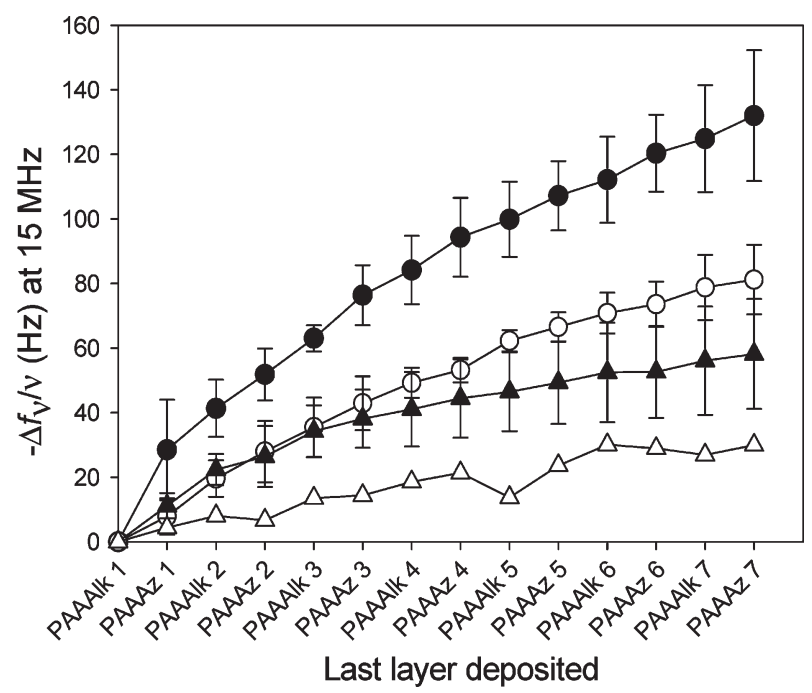

Figure 5. Evolution of the normalized frequency shift, measured at $15 \mathrm{MHz}(v=3)$ by EC-QCM, as a function of the adsorbed polyelectrolyte layers for the $\mathrm{PAA}_{\mathrm{Alk}} / \mathrm{PAA}_{\mathrm{Az}}$ system built in the presence of $\mathrm{CuSO}_{4}$ at $0.3(\bullet), 0.15(\bigcirc), 0.075(\Delta)$, and $0.05 \mathrm{mM}(\triangle)$. During the adsorption of PAA $\mathrm{Alk}_{\mathrm{k}}$ and $\mathrm{PAA}_{\mathrm{Az}}$, an electric potential $E$ of $-350 \mathrm{mV}$ was applied. In the case of $\mathrm{CuSO}_{4}$ concentrations less than $0.3 \mathrm{mM}$ of $\mathrm{NaNO}_{3}$ salt was added in aqueous solution to maintain the ionic strength constant at $1.2 \mathrm{mM}$ (i.e., the ionic strength of $0.3 \mathrm{mM}$ of $\mathrm{CuSO}_{4}$ ). For the concentrations equal to or larger than $0.075 \mathrm{mM} \mathrm{CuSO}_{4}$, the mean and the standard deviation of at least three experiments are represented. $\mathrm{A} \mathrm{PEI}_{\mathrm{Az}}$ precursor layer is used to anchor the films onto the substrate. The crystal frequency corresponding to the first $\mathrm{PAA}_{\mathrm{Alk}}$ deposition is taken as reference.

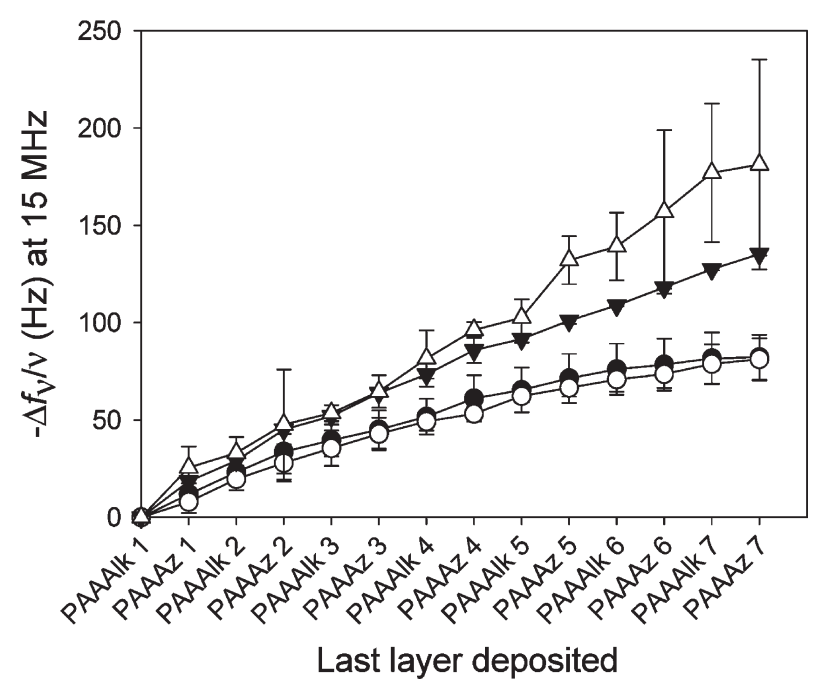

Figure 6. Evolution of the normalized frequency shift, measured at $15 \mathrm{MHz}(v=3)$ by EC-QCM, as a function of the adsorbed polyelectrolyte layers for the $\mathrm{PAA}_{\mathrm{Alk}} / \mathrm{PAA}_{\mathrm{Az}}$ system built in the presence $0.15 \mathrm{mM} \mathrm{CuSO}_{4}$ at a reduction potential $E$ of $-350 \mathrm{mV}$ applied for $2(\bullet), 5(\bigcirc), 7(\nabla)$, and $20 \mathrm{~min}(\triangle)$. For each reduction time, the average and the standard deviation from at least three experiments are represented. $\mathrm{NaNO}_{3}$ salt was added in the aqueous solution of $\mathrm{CuSO}_{4}$ to have a constant ionic strength of $1.2 \mathrm{mM}$. A $\mathrm{PEI}_{\mathrm{Az}}$ precursor layer is used to anchor the films onto the substrate. The crystal frequency corresponding to the first $\mathrm{PAA}_{\mathrm{Alk}}$ deposition is taken as reference.

relationship between $n$ and $\Delta t_{E}$ is however out of the scope of this paper. 

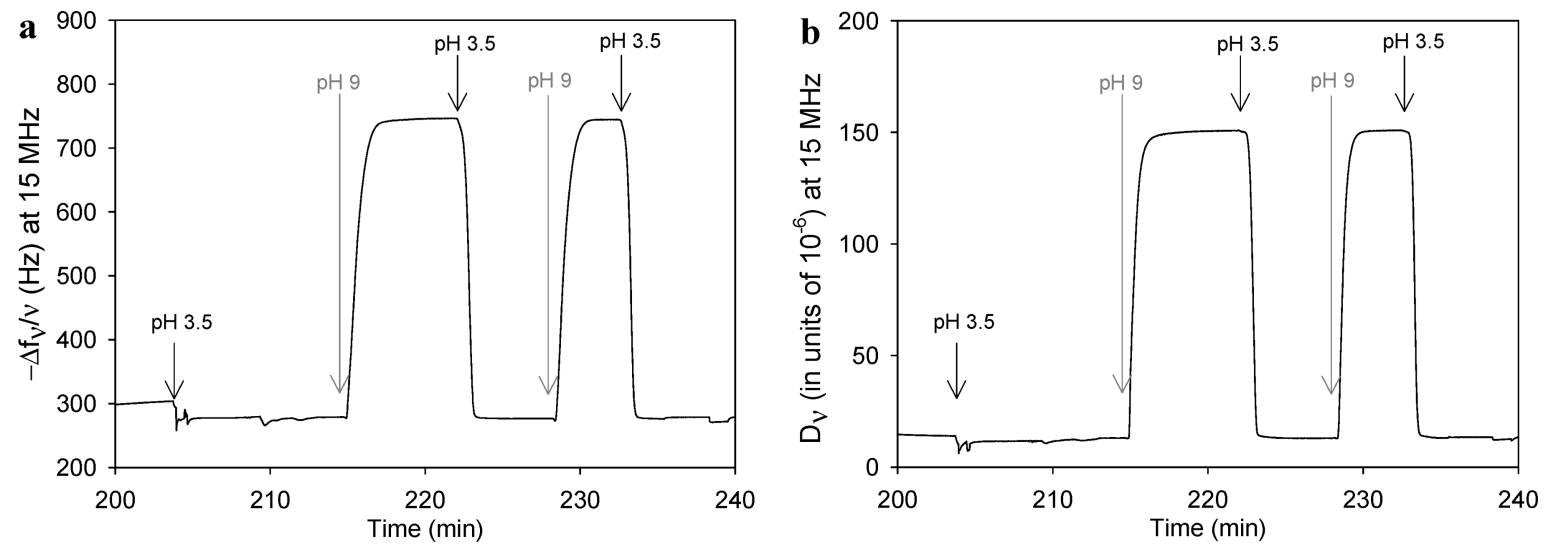

Figure 7. (a) Evolution of the normalized frequency shift and (b) dissipation, measured at $15 \mathrm{MHz}(v=3)$ by EC-QCM, of a PEI $\mathrm{Az}^{-}\left(\mathrm{PAA}_{\mathrm{Alk}} /\right.$ $\left.\mathrm{PAA}_{\mathrm{Az}}\right)_{7}$ film, constructed built in the presence of $0.3 \mathrm{mM} \mathrm{CuSO}_{4}$ at $\mathrm{pH} 3.5$ with $E=-350 \mathrm{mV}$, in contact with solutions of $10 \mathrm{mM} \mathrm{NaNO}$ at $\mathrm{pH} 3.5$ and 9 as a function of time. The contact of the different solutions was operated under a flow rate of $1.4 \mathrm{~mL} / \mathrm{min}$.

Stability of the Films with Respect to Swelling. To test the stability and robustness of the multilayers, $\mathrm{pH}$ jumps were performed on a film constructed in the presence of $0.3 \mathrm{mM}$ $\mathrm{CuSO}_{4}$ at $\mathrm{pH} 3.5$ with $E=-350 \mathrm{mV}$ by changing the $\mathrm{pH}$ of the contacting solution from 3.5 to 9 in the presence of $10 \mathrm{mM}$ $\mathrm{NaNO}_{3}$. The $\mathrm{pH}$ was then brought back to its initial value (i.e., $\mathrm{pH} 3.5$ ) in order to test the reversibility of the $\mathrm{pH}$ response. Parts a and $\mathrm{b}$ of Figure 7 represent respectively the evolution of the normalized frequency shift and dissipation of a $\mathrm{PEI}_{\mathrm{Az}}-\left(\mathrm{PAA}_{\mathrm{Alk}} /\right.$ $\left.\mathrm{PAA}_{\mathrm{Az}}\right)_{7}$ film determined by QCM. The film swells in a reversible and reproducible manner as the $\mathrm{pH}$ is increased. These observations are in agreement with those of Tang et al. ${ }^{35}$ and are expected since the carboxylic groups become ionized as the $\mathrm{pH}$ is increased. The reversibility of the swelling indicates that no material is lost during swelling. The film is thus robust with respect to internal mechanical stress as expected from covalently bond architectures.

By treating the data with the Voigt model, ${ }^{56}$ the best fit to the data gives a film thickness, at $\mathrm{pH} 3.5$ and 9, respectively of 55 and $200 \mathrm{~nm}$, leading to a swelling ratio of 3.6 with an elasticity of 444 and $192 \mathrm{kPa}$ and a viscosity of 9.6 and $6.7 \mathrm{mPa} \cdot \mathrm{s}$ at $\mathrm{pH} 3.5$ and 9, respectively. The swelling ratio is defined as the ratio of the film thickness at $\mathrm{pH} 9$ to that at $\mathrm{pH}$ 3.5. Two additional experiments were performed to test the reproducibility of the swelling experiments. They gave respectively 62 and $65 \mathrm{~nm}$ at $\mathrm{pH} 3.5$ and 216 and $220 \mathrm{~nm}$ at $\mathrm{pH} 9$ (with a swelling ratio of 3.5 for both).

Topography of the $\mathbf{P A} \mathbf{A}_{\mathrm{Alk}} / \mathbf{P A} \mathbf{A}_{\mathrm{Az}}$ Film. The topography of a PEI-(PAA $\left.A_{\mathrm{Alk}} / \mathrm{PAA}_{\mathrm{Az}}\right)_{7}$ film built by electrochemically catalyzed click chemistry was imaged by AFM in liquid state. The film was constructed at a reduction potential of $-350 \mathrm{mV}$ with a $\mathrm{Cu}$ (II) concentration of $0.3 \mathrm{mM}$ at $\mathrm{pH} 3.5$ and the AFM images were taken in the presence of $10 \mathrm{mM} \mathrm{NaNO}_{3}$ at $\mathrm{pH} 3.5$ and $\mathrm{pH} 9$. The film appears homogeneous with a surface roughness that can be estimated from a $10 \mu \mathrm{m} \times 10 \mu \mathrm{m}$ AFM image (rms) to be of the order of 6 and $12 \mathrm{~nm}$ respectively at $\mathrm{pH} 3.5$ and at $\mathrm{pH}$ 9. By scratching the film, the AFM image allows determining the film thickness.

Figure 8 shows a typical image of the scratched film (a) and the corresponding profile (b). The substrate appears entirely covered. The thickness of the film is of the order of $40 \mathrm{~nm}$ at $\mathrm{pH} 3.5$. This film was then brought in contact with a solution at $\mathrm{pH} 9$. The swelling observed by QCM is confirmed by AFM (Figure 8c,d), giving a thickness of $140 \mathrm{~nm}$ with a swelling ratio of the order of 3.5 , close to that found by QCM. It can be noticed that to perform the scratch we had to build the film with a PEI precursor layer instead of a $\mathrm{PEI}_{\mathrm{Az}}$ precursor layer. In this latter case the scratch- ing was extremely difficult, indicating again the robustness of these films. With a PEI precursor layer, the scratching was much easier because the first PEI layer interacts with the PAA $\mathrm{Alk}_{\mathrm{k}}$ only through electrostatic interactions.

\section{Discussion}

The click reaction takes place only in the presence of $\mathrm{Cu}(\mathrm{I})$ which is produced at the electrode by the reduction of $\mathrm{Cu}$ (II). It has been shown by the non-buildup of the film while the polyelectrolytes were brought in contact with the film only once the $+600 \mathrm{mV}$ potential was applied. The film buildup is thus governed by the rate at which the polyelectrolytes and the $\mathrm{Cu}(\mathrm{I})$ ions reach the film/solution interface where the click reaction takes place. The polyelectrolytes diffuse from the solution toward the interface whereas the $\mathrm{Cu}(\mathrm{I})$ ions diffuse from the electrode toward the same interface. As the polyelectrolytes reach the interface, they start to form covalent bonds with the film. A single chain becomes gradually anchored onto the film through the reaction of its azide or alkyl functions. The characteristic time needed for a single chain to establish its maximum of covalent links depends upon the click reaction kinetics. When the $\mathrm{Cu}(\mathrm{I})$ concentration is higher, the click reaction is faster and thus the anchoring time of a single chain is shorter. If during this anchoring time a new chain diffuses in the vicinity of the one that is in the process of anchoring, it can also establish covalent bonds with the film, thus leading to steric repulsion between chains. In this case, each chain establishes fewer links with the surface compared to the case where a single chain deposits, leading to a more "loopy" conformation of the chains and then to higher deposited mass at each deposition steps. Increasing the $\mathrm{Cu}$ (II) concentration leads to two opposite effects. On the one hand, a faster reaction induces faster deposition of a single chain which can thus block the incoming of new ones, leading to a reduction of the deposited mass. On the other hand, a faster reaction also promotes a more rapid anchoring of several chains leading to an increase of the mass deposited. Our experiments show that it is the second effect, namely an increase of the film growth, that dominates. This mechanism also implies that when keeping the $\mathrm{Cu}$ (II) concentration fixed, the film thickness should increase when increasing the polyelectrolyte concentration in the solution, as it was observed experimentally. Indeed, increasing the polyelectrolyte concentration in solution also enhances the probability of a new chain to anchor in the vicinity of an already partially anchored chain leading to an increase of the final deposited polymer mass (Figure S-5 in Supporting Information). 

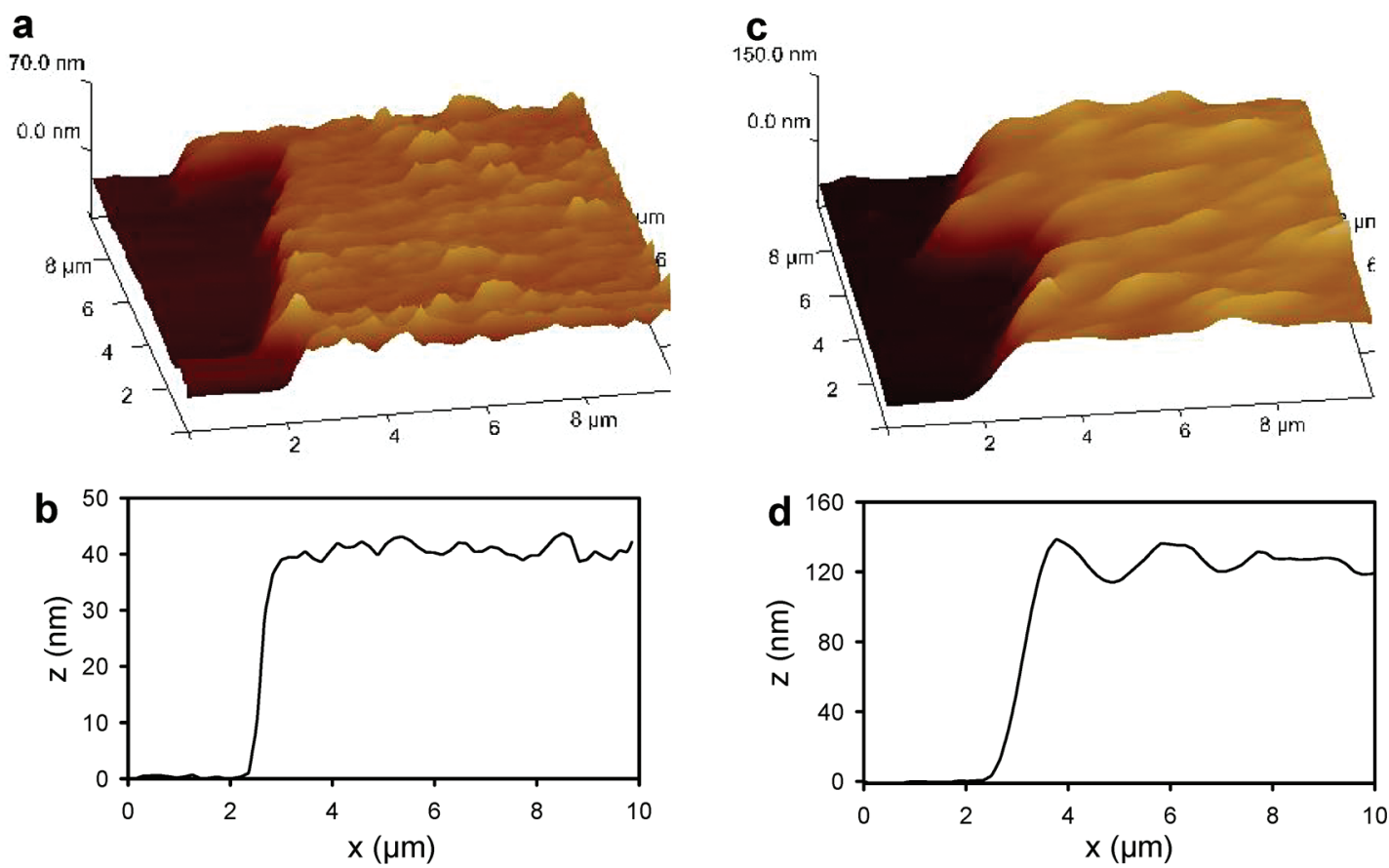

Figure 8. Typical AFM height 3D images $(10 \mu \mathrm{m} \times 10 \mu \mathrm{m})$, obtained in contact mode, of PEI-(PAA $\left.\mathrm{Plk} / \mathrm{PAA}_{\mathrm{Az}}\right)_{7}$ in liquid state built in the presence of $0.3 \mathrm{mM} \mathrm{CuSO}_{4}$ with $E=-350 \mathrm{mV}$. Scratch of the film and cross-section profiles imaged at (a, b) pH $3.5 \mathrm{and}$ (c, d) pH 9.

Let us now discuss the existence of a leveling off of the film buildup (see Figure S-4 in Supporting Information). This leveling off can have two origins. After a given number of deposition steps, the new incoming polyelectrolyte chains might interact with the surface through all their azide or alkyne groups so that no more groups are available for a subsequent reaction. The buildup then automatically stops. The leveling off might also come from a too small $\mathrm{Cu}(\mathrm{I})$ concentration at the film/solution interface so that the click reaction can no longer take place. In order to check whether the leveling off is due to the absence of azide or alkyne groups on the surface, we performed the following experiment: a film was built at $0.15 \mathrm{mM}$ of $\mathrm{CuSO}_{4}$ with a reduction time of $2 \mathrm{~min}$. The leveling off sets in after $6 \mathrm{PAA}_{\mathrm{Alk}} / \mathrm{PAA}_{\mathrm{Az}}$ pairs of layers (see Figure S-6 of Supporting Information). We then increased the $\mathrm{Cu}(\mathrm{II})$ concentration in solution and remained the reduction time constant. We observe that the film buildup takes place again, clearly indicating the presence of available azide or alkyne groups on the surface. Finally, we blocked all the alkyne groups on the surface by reacting them through a click reaction with $\mathrm{EG}_{3} \mathrm{Az}$ (2-(2-(2-azidoethoxy)ethoxy)ethanol) compound prepared according to Patel et al. ${ }^{57}$ When this film was further brought in contact with PAA $_{\mathrm{Az}}$ chains, no deposition could be observed anymore. This clearly indicates that the film no longer builds up after the reaction of all alkyne groups. Concerning the leveling off observed after the deposition of six pairs of layers, we can thus conclude that it is not due to the absence of available azide or alkyne groups on the surface. This might be due to a too small $\mathrm{Cu}(\mathrm{I})$ concentration at the film/solution interface to obtain the click reaction. Indeed, this reaction is known to be of order 2 with respect to the $\mathrm{Cu}(\mathrm{I})$ concentration $^{58}$ and thus very sensitive to the $\mathrm{Cu}(\mathrm{I})$ concentration. $\mathrm{Cu}(\mathrm{I})$ ions have to diffuse up to the interface to form covalent bonds between polyelectrolytes and the film. If during the reduction time $\mathrm{Cu}(\mathrm{I})$ ions cannot reach the interface,

(57) Patel, K.; Angelos, S.; Dichtel, W. R.; Coskun, A.; Yang, Y. W.; Zink, J. I.; Stoddart, J. F. J. Am. Chem. Soc. 2008, 130, 2382.

(58) Rodionov, V. O.; Fokin, V. V.; Finn, M. G. Angew. Chem., Int. Ed. 2005, 44,2210 . the buildup process levels off. The leveling off should take place after a smaller number of pairs of layers for smaller $\mathrm{Cu}$ (II) concentration. This is in accordance with the experimental observations (Figure S-4a). One also expects that, as the reduction time is increased, the number of deposited layers required for leveling off also increases, again in accordance with our observations (Figure S-4b). The leveling off sets in roughly for a film thickness $X$ of the order of $30 \mathrm{~nm}$ for a reduction time of $\Delta t_{E}=$ $5 \mathrm{~min}$. This allows to get a rough estimate of the diffusion coefficient $D_{\mathrm{Cu}}$ of $\mathrm{Cu}(\mathrm{I})$ in the film $\left(X^{2}=2 D \Delta t_{E}\right)$, which is of the order of $10^{-14} \mathrm{~cm}^{2} \mathrm{~s}^{-1}$. This value is much smaller than the typical value of $10^{-6} \mathrm{~cm}^{2} \mathrm{~s}^{-1}$ for ions in aqueous solutions. It is of the same order of magnitude as that of methylene blue in poly(styrenesulfonate)/poly(allylamine) multilayers ${ }^{59}$ found to be of the order of $10^{-15} \mathrm{~cm}^{2} \mathrm{~s}^{-1}$ and at least 3 orders of magnitude higher than that of other dyes in poly(styrenesulfonate)/poly(vinylbenzyl chloride) quaternized with $N, N$-dimethylethanolamine multilayers ${ }^{60}$ found to be of the order $10^{-17}-10^{-18} \mathrm{~cm}^{2} \mathrm{~s}^{-1}$. In this latter case, the dyes are expected to interact strongly through $\pi-\pi$ interactions with the styrene rings from the polyelectrolytes in addition to electrostatic interactions. In our case the small value of the diffusion coefficient could be due to the interactions of the diffusing species, $\mathrm{Cu}$ (I) and $\mathrm{Cu}(\mathrm{II})$, in the film with carboxylic groups. These groups hinder free diffusion of cations in accordance with the ion transport model in polyelectrolyte multilayers developed by Schlenoff. ${ }^{61}$ Finally, the click reaction is not instantaneous, and one would have to take the reaction kinetics into account. All these factors reduce the diffusion of ions through the film.

\section{Conclusion}

To summarize, we have shown that multilayers with polyelectrolytes of same charge modified by grafting either alkyne or azide

(59) von Klitzing, R.; Möhwald, H. Macromolecules 1996, 29, 6901.

(60) Nicol, E.; Habib-Jiwan, J. L.; Jonas, A. M. Langmuir 2003, 19, 6178.

(61) Farhat, T. R.; Schlenoff, J. B. Langmuir 2001, 17, 1184. 
groups can be constructed through a rapid and efficient electrochemically triggered Sharpless reaction. This new procedure allows the buildup of multilayer films in the absence of chemical reducing agent or $\mathrm{Cu}(\mathrm{I})$ - organic ligands and allows the construction of multilayers with components that do not interact via electrostatic attraction or hydrogen bonding. These films can be constructed on electrodes whose potentials are more negative than a critical value that lies between -70 and $-150 \mathrm{mV}$ vs $\mathrm{Ag} /$ $\mathrm{AgCl}$ ( $\mathrm{KCl}$ sat.) reference electrode. The film thickness increment per pair of layers appears independent of the applied voltage as long as it is more negative than a critical value but depends upon $\mathrm{Cu}$ (II) and polyelectrolyte concentrations in solution and upon the reduction time of $\mathrm{Cu}(\mathrm{II})$. An increase of any of the mentioned parameters leads to an increase of the thickness per bilayer. For given buildup conditions, the construction levels off after a given number of deposition steps which increases with the $\mathrm{Cu}$ (II) concentration in solution and with the reduction time. A model based on the diffusion of $\mathrm{Cu}(\mathrm{II})$ and $\mathrm{Cu}(\mathrm{I})$ through the film is proposed to explain these experimental observations. This study was intended to make the proof of principle of the buildup procedure and to get first indications of the parameters affecting the multilayer buildup. Further studies are however needed to precisely understand the role of each parameter and to be able to model the buildup process. Such studies are currently under way.

Acknowledgment. We thank David Martel and Hoan Cong Nguyen (UMR 7177, CNRS/UdS Strasbourg, France) for fruitful discussions. Financial support from ANR ClickMultilayer ANR-07-BLAN-0169, ANR E-DETACHPEM BLAN081_315174, and Centre National de la Recherche Scientifique are also acknowledged. N.B.A. is indebted to the Université de
Strasbourg for her fellowship. The contributions of the different authors are as follows: P.S. initiated the project, F.B. came up with the concept, and G.R. performed the experiments of QCM. J.-S.T. and NBA performed the synthesis of the polymers, B.F supervised the synthesizes, P.S. and F.B. supervised the work, C.C. and A.E.H. performed the AFM images, A.P. performed the XPS experiments, G.R., L.J., P.M., J.-C.V., B.S., B.F., P.S., and F.B. participated actively in the discussions about the results, and F.B. and P.S. wrote the paper.

Supporting Information Available: Detailed synthesis of $\mathrm{PEI}_{\mathrm{Az}}, \mathrm{PAA}_{\mathrm{Alk}}$, and $\mathrm{PAA}_{\mathrm{Az}}$; evolution of the normalized frequency shift measured by EC-QCM as a function of time during two successive cycles of -350 and $+600 \mathrm{mV}$ on a $\mathrm{PEI}_{\mathrm{Az}}-\left(\mathrm{PAA}_{\mathrm{Alk}} / \mathrm{PAA}_{\mathrm{Az}}\right)_{7}$ film; XPS and X-ray-induced Auger spectroscopy of $\mathrm{PEI}_{\mathrm{Az}}-\left(\mathrm{PAA}_{\mathrm{Alk}} / \mathrm{PAA}_{\mathrm{Az}}\right)_{14}$ film; evolution of the normalized frequency shift for $\mathrm{PAA}_{\mathrm{Alk}} / \mathrm{PAA}_{\mathrm{Alk}}$ and PAA/PAA systems on $\mathrm{PEI}_{\mathrm{Az}}$ in electrochemically catalyzed click chemistry conditions and for $\mathrm{PAA}_{\mathrm{Alk}} / \mathrm{PAA}_{\mathrm{Az}}$ system with injection of polyelectrolytes at $+600 \mathrm{mV}$; buildup of $\left(\mathrm{PAA}_{\mathrm{Alk}} / \mathrm{PAA}_{\mathrm{Az}}\right)_{14}$ at different $\mathrm{CuSO}_{4}$ concentrations in electrochemically catalyzed click chemistry conditions; evolution of the normalized frequency shift of $\mathrm{PEI}_{\mathrm{Az}^{-}}$ $\left(\mathrm{PAA}_{\mathrm{Alk}} / \mathrm{PAA}_{\mathrm{Az}}\right)_{7}$ film as a function of the adsorbed polyelectrolyte layers built at different polyelectrolyte concentration; evolution of the normalized frequency shift as a function of the adsorbed polyelectrolyte layers for the $\mathrm{PAA}_{\mathrm{Alk}} / \mathrm{PAA}_{\mathrm{Az}}$ system built in the presence of $\mathrm{CuSO}_{4}$ at $0.15 \mathrm{mM}$ followed by a buildup at $0.3 \mathrm{mM}$. This material is available free of charge via the Internet at http:// pubs.acs.org. 